University of Windsor

Scholarship at UWindsor

Jun 6th, 9:00 AM - Jun 9th, 5:00 PM

\title{
Dialectical Profiles and Indicators of Argumentative Moves
}

Frans $\mathrm{H}$. van Eemeren

University of Amsterdam

Peter Houtlosser

University of Amsterdam

A Francisca Snoeck Henkemans

University of Amsterdam

Follow this and additional works at: https://scholar.uwindsor.ca/ossaarchive

Part of the Philosophy Commons

van Eemeren, Frans H.; Houtlosser, Peter; and Snoeck Henkemans, A Francisca, "Dialectical Profiles and Indicators of Argumentative Moves" (2007). OSSA Conference Archive. 37.

https://scholar.uwindsor.ca/ossaarchive/OSSA7/papersandcommentaries/37

This Paper is brought to you for free and open access by the Conferences and Conference Proceedings at Scholarship at UWindsor. It has been accepted for inclusion in OSSA Conference Archive by an authorized conference organizer of Scholarship at UWindsor. For more information, please contact scholarship@uwindsor.ca. 


\title{
Dialectical Profiles and Indicators of Argumentative Moves
}

\section{FRANS H. VAN EEMEREN, PETER HOUTLOSSER and A. FRANCISCA SNOECK HENKEMANS}

\author{
Department of Speech Communication, Argumentation Theory and Rhetoric \\ University of Amsterdam \\ Amsterdam, The Netherlands \\ f.h.vaneemeren@uva.nl \\ p.houtlosser@uva.nl \\ a.f.snoeckhenkemans@uva.nl
}

\begin{abstract}
In this paper the authors give a brief overview of the theoretical background of their research project "Linguistic indicators of argumentative moves." Starting from the pragma-dialectical ideal model of a critical discussion, they design dialectical profiles for capturing the moves that may or must be made at a particular stage or sub-stage of such a discussion. They explain how these dialectical profiles can be methodically exploited for systematically identifying the verbal expressions that can be indicative of any of these moves in argumentative practice.
\end{abstract}

KEY WORDS: argumentation, critical discussion, dialectical profile, linguistic indicator, pragma-dialectics.

\section{A PRAGMA-DIALECTICAL PERSPECTIVE ON ARGUMENTATIVE DISCOURSE}

The study of argumentation is prospering. After its brilliant start in Antiquity, highlighted in the classical works of Aristotle, after an alternation of ups and downs during the following millennia, in the post-Renaissance period its gradual decline set in. Revitalization took place only after Toulmin and Perelman published in the same year (1958) their landmark works The Uses of Argument and La nouvelle rhétorique (co-authored by Olbrechts-Tyteca and translated into English in 1969). The model of argumentation presented by Toulmin and Perelman's inventory of argumentation techniques inspired a great many scholars in various ways to take up the study of argumentation in a serious manner. Nowadays there are well-established (formal as well as informal) logical approaches to argumentation, but also social and socio-psychological, linguistic, juridical and other approaches. In most of these approaches traces can be found of the influence of the classical and neo-classical argumentation theories just mentioned. ${ }^{1}$

The most important characteristic of the pragma-dialectical approach to argumentation that we represent is that argumentation is studied from a communicative perspective. Argumentation is viewed as a type of communication aimed at resolving a difference of opinion by critically testing the acceptability of the standpoints at issue. Generally, this communication will take place by verbal means, whether oral or written, but non-verbal elements (such as gestures and images) may also play a part. In practice, the term argumentation is used in two ways at the same time: it refers to a process ("I am still in the middle of my argumentation") as well as to its result ("Let's examine what her argumentation amounts to"). Because argumentation is not just part of reality, but can, and should, also be judged for its quality, the study of argumentation has not only a descriptive but also a normative dimension. According to pragma-dialecticians, the quality of

\footnotetext{
${ }^{1}$ For a more elaborate description of the history of the study of argumentation and the current state of the art, see van Eemeren et al. (1996) and van Eemeren (Ed. 2002).

Eemeren, F.H. van, Houtlosser, P. \& Snoek Henkemans, A.F. (2007). Dialectical profiles and indicators of argument moves. In H.V. Hansen, et. al. (Eds.), Dissensus and the Search for Common Ground, CD-ROM (pp. 1-17). Windsor, ON: OSSA.

Copyright (c) 2007, the authors.
} 
argumentation and its possible flaws are to be measured against norms of reasonableness that are suited to its purpose.

Logicians, whether they are in favor of a formal or an informal approach, tend to concentrate on the problems involved in the regimentation of reasoning. Social scientists and linguists, particularly discourse and conversation analysts, generally focus on empirical observation of argumentative discourse and its effects. In the pragma-dialectical view, however, these two approaches must be closely interwoven. Both the limitations of non-empirical regimentation and those of non-critical observation need to be systematically transcended. Pragma-dialecticians make it their business to clarify how the gap between normative and descriptive insight can be methodically bridged. This objective can only be achieved with the help of a coherent research program in which a systematic connection - a trait d'union - is created between well-considered regimentation and careful observation.

Following a classical tradition, the study of the regimentation of critical exchanges is called dialectics. The study of language use in actual communication, which belonged in the past largely to the domain of rhetoric, is nowadays generally called pragmatics. Hence the choice of the name pragma-dialectics for the approach to argumentation that aims for a sound integration of insight from these two studies. Pragma-dialectics combines a dialectical view of argumentative reasonableness with a pragmatic view of the verbal moves made in argumentative discourse. $^{2}$

Pragma-dialectics starts from four meta-theoretical principles, functionalization, socialization, externalization, and dialectification of argumentation, in which pragmatic and dialectical insights are systematically combined. Functionalization is achieved by making use of the fact that argumentative discourse occurs through - and in response to - speech act performances. Identifying the complex speech act of argumentation and the other speech acts involved in resolving a difference of opinion makes it possible to specify the relevant "identity conditions" and "correctness conditions" of these speech acts. ${ }^{3}$ In this way, for instance, a specification can be given of what is "at stake" in advancing a certain "standpoint," so that it becomes clear what the "disagreement space" is and how the argumentative discourse is organized around this context of disagreement. ${ }^{4}$ Socialization is achieved by identifying who exactly take on the discussion roles of protagonist and antagonist in the collaborative context of argumentative discourse. By extending the speech act perspective to the level of interaction, it can be shown in which ways positions and argumentation in support of positions are developed. Externalization is achieved by identifying the specific commitments that are created by the speech acts performed in a context of argumentative interaction. ${ }^{5}$ Rather than being treated as internal states of mind, in a speech act perspective notions such as "disagreement" and "acceptance" can be defined in terms of discursive activities. "Acceptance," for instance, can be externalized as giving a preferred response to an arguable act. Finally, dialectification is achieved by regimenting the exchange of speech acts aimed at resolving a difference of opinion in a model

\footnotetext{
2 The dialectical conception of reasonableness is inspired by critical rationalists and analytic philosophers, such as Popper (1972, 1974), Albert (1975), and Naess (1966), and by formal dialecticians and logicians, such as Hamblin (1970), Lorenzen and Lorenz (1978), and Barth and Krabbe (1982). The pragmatic conception of argumentative discourse as consisting of making regulated communicative moves is rooted in Austin (1962) and Searle's (1969, 1979) ordinary language philosophy, Grice's (1989) theory of rationality in discourse, and other studies of communication by discourse and conversation analysts. It is in the first place the combination of dialectical and pragmatic insight that distinguishes pragma-dialectics from "formal dialectics" as developed by Barth and Krabbe (1982) that incorporates dialectical insight in a formal (logical) approach.

${ }^{3}$ For a definition of argumentation as a complex speech act, see van Eemeren and Grootendorst (1984, pp. 39-46, 1992a, pp. 30-33). For the speech act of advancing a standpoint, see Houtlosser (1994). And for the distinction between identity conditions and correctness conditions, see van Eemeren and Grootendorst (1992a, pp. 30-31).

${ }^{4}$ The term disagreement space was introduced in Jackson (1992, p. 261).

${ }^{5}$ A kindred approach to argumentation in which commitments as well as other basic concepts of pragma-dialectics also play a crucial role is Walton and Krabbe (1995).
} 
of a perfect critical discussion. Such an idealized modeling of the systematic exchanges of resolution-oriented verbal moves, defines the nature and distribution of the speech acts that play a part in resolving a difference of opinion.

The pragma-dialectical model of a critical discussion is a theoretically motivated system for resolution-oriented discourse. In a critical discussion, the parties attempt to reach agreement about the acceptability of the standpoints at issue by finding out whether or not these standpoints are defensible against doubt or criticism. The dialectical procedure for conducting a critical discussion is in the first place a method for exploring the acceptability of standpoints. In a critical discussion, the protagonist and the antagonist of a particular standpoint try to establish whether this standpoint, given the point of departure acknowledged by the parties, is tenable in the light of critical responses. ${ }^{6}$ To be able to achieve this purpose, the dialectical procedure for conducting a critical discussion should not deal only with inference relations between premises and conclusions (or "concessions" and "standpoints"), but cover all speech acts that play a part in examining the acceptability of standpoints. In pragma-dialectics, the concept of a critical discussion is therefore given shape in a model that specifies all the various stages the resolution process has to pass and all the types of speech acts instrumental in any of these stages. When pointing out the roles that various types of speech acts can fulfill in resolving a difference of opinion it is important to emphasize, right from the start, that in argumentative discourse a great many speech acts are performed implicitly or indirectly, so that a certain role in a critical discussion may be fulfilled by different speech acts.

In pragma-dialectics, the critical norms of reasonableness authorizing the speech acts performed in the various stages of a critical discussion are accounted for in a set of dialectical rules. Taken together, the model and the rules constitute a theoretical definition of a critical discussion. In a critical discussion, the protagonists and the antagonists of the standpoints at issue not only go through all stages of the resolution process, but they must also observe in every stage all the rules that are instrumental in resolving a difference of opinion. ${ }^{7}$ The dialectical procedure proposed by van Eemeren and Grootendorst $(1984,2004)$ states the rules that are constitutive for a critical discussion in terms of the performance of speech acts. ${ }^{8}$ They cover the entire argumentative discourse by stating all the norms that are pertinent to resolving a difference of opinion, ranging from the prohibition to prevent each other from expressing any position one wishes to assume in the confrontation stage, to the prohibition to unduly generalize the result of the discussion in the concluding stage.

In principle, each of the pragma-dialectical discussion rules constitutes a distinct standard or norm for critical discussion. Any move constituting an infringement of any of the rules, whichever party performs it and at whatever stage in the discussion, is a possible threat to the resolution of a difference of opinion and must therefore (in this particular sense) be regarded as

\footnotetext{
${ }^{6}$ In accordance with their critical rationalist philosophy, dialecticians place great emphasis on the consequence of the fact that a proposition and its negation cannot both be acceptable at the same time. The testing of standpoints is thus equated with the detection of inconsistencies (Albert 1975, p. 44).

${ }^{7}$ If the rules of the pragma-dialectical discussion procedure are regarded as first order conditions for having a critical discussion, the internal conditions for a reasonable discussion attitude can be viewed as "second order" conditions relating to the state of mind the discussants are assumed to be in. In practice, people's freedom to satisfy the second order conditions is sometimes limited by psychological factors beyond their control, such as emotional restraint and personal pressure. There are also external, "third order" conditions that need to be fulfilled in order to be able to conduct a critical discussion properly. They relate to the social circumstances in which the discussion takes place and pertain, for instance, to the power or authority relations between the participants and to the discussion situation. Together, the second and third order conditions for conducting a critical discussion in the ideal sense are higher order conditions for resolving differences of opinion. Only if these conditions are satisfied critical reasonableness can be fully realized in practice.

${ }^{8}$ An improved version of the pragma-dialectical rules for critical discussion is to be found in van Eemeren and Grootendorst (2004, ch. 6).
} 
fallacious. ${ }^{9}$ The use of the term fallacy is then systematically connected with the rules for critical discussion and a fallacy is defined as a discussion move that violates in some specific way a rule for critical discussion applying to a particular discussion stage.

For various reasons, argumentative reality does not always resemble the ideal of a critical discussion. In order to be able to give a sound evaluation of argumentative discourse with the help of the model of a critical discussion, an analysis is needed that makes it clear which elements in the discourse can be considered potentially relevant for he resolution of the dispute. According to the ideal model, for example, in the confrontation stage antagonists of a standpoint must state their doubts clearly and unambiguously, but in practice doing so can be "facethreatening" for both parties so that they have to operate circumspectly. ${ }^{10}$ Analyzing argumentative discourse pragma-dialectically amounts to interpreting the discourse from the theoretical perspective of a critical discussion. Such an analysis is pragmatic in viewing the discourse as essentially an exchange of speech acts; and dialectical in viewing this exchange as a methodical attempt to resolve a difference of opinion. A pragma-dialectical analysis is aimed at reconstructing all those, and only those, speech acts that play a potential part in bringing a difference of opinion to a conclusion. In accomplishing a systematic analysis the ideal model of a critical discussion is a valuable tool. By pointing out which speech acts are relevant in the various stages of the resolution process the model has the heuristic function of indicating which speech acts need to be considered in the reconstruction.

Van Eemeren, Grootendorst, Jackson and Jacobs further developed the analytical component of pragma-dialectics in Reconstructing Argumentative Discourse (1993). They emphasize that it is crucial that the reconstructions proposed in the analysis are indeed justified. The reconstructions should be faithful to the commitments that may be ascribed to the participants on the basis of their contributions to the discourse. ${ }^{11}$ In order not to "over-interpret" what seems implicit in the discourse, the analyst must be sensitive to the rules of language use, ${ }^{12}$ the details of the presentation, and the contextual constraints inherent in the speech event concerned. So as to go beyond a naïve reading of the discourse, empirical insight concerning the way in which oral and written discourse are conducted will be beneficial. ${ }^{13}$ The analyst's intuitions can thus be augmented by the results of (qualitative and quantitative) empirical research. $^{14}$

In the analysis of argumentative discourse linguistic indicators of the various moves that are potentially relevant for the resolution of a dispute play a crucial role. During the past decade we have carried out a research project that we dubbed the "indicator project." The central question of the indicator project was what verbal means arguers use to indicate the functions of the various moves that are made in an argumentative discussion or text. The aim of the research was to identify these words and expressions, to classify them in accordance with the argumentative function they can have in argumentative discourse and to determine under which conditions they will fulfill a certain function. In this paper, we intend to explain the main

\footnotetext{
${ }^{9}$ The pragma-dialectical identification of fallacies is always conditional. An argumentative move may be regarded as a fallacy only if the discourse is correctly viewed as aimed at resolving a difference of opinion.

${ }^{10}$ Expressing doubt may also create a potential violation of the "preference for agreement" that governs normal conversation. See Heritage (1984, pp. 265-280), Levinson (1983, pp. 332-336), and van Eemeren, Grootendorst, Jackson, and Jacobs (1993, ch. 3).

${ }^{11}$ Only in exceptional cases, when interpreting a move as a potential contribution to the resolution process is the only charitable option left, an unsupported reconstruction may be warranted “for reason's sake." See van Eemeren and Grootendorst (2004, ch. 5).

${ }^{12}$ An integration of the Searlean speech act conditions and the Gricean conversational maxims in a set of "rules of language use” is proposed in van Eemeren and Grootendorst (1992a, pp. 49-55, 2003, ch.4).

${ }^{13}$ See, e.g., Jackson and Jacobs (1980) and Jacobs and Jackson (1981, 1982, 1983).

${ }^{14}$ For a brief survey of the various approaches to the analysis of discourse and their empirical basis, see van Eemeren, Grootendorst, Jackson, and Jacobs (1993, pp. 50-59).
} 
theoretical and methodological premises of the indicator project. Starting from these premises we also want to illustrate by means of some examples how we conducted our research (van Eemeren, Houtlosser and Snoeck Henkemans 2000, 2005; Houtlosser 1997, 2002; Snoeck Henkemans 2001, 2003a, 2003b).

\section{ARGUMENTATIVE INDICATORS AND THE MODEL OF A CRITICAL DISCUSSION}

For three reasons the pragma-dialectical model of a critical discussion constitutes an appropriate starting point for the description of argumentative indicators. First, starting from the assumption that argumentative discussions and texts are always - at least to some extent - aimed at resolving a difference of opinion on the merits, the model of a critical discussion can be considered a blueprint of the crucial tasks that the participants have to carry out in order to resolve a difference of opinion in a critical testing process. All the tasks specified in the model are functional in a critical testing process and should ideally be carried out in some way or other, even if in practice they are sometimes only fulfilled in an implicit or incomplete way, or even not at all. It is in fact precisely in those cases where the fulfillment of these tasks is not explicitly or completely manifest in the discourse that the model has a special function. Second, precisely because the model provides a specification of all speech acts that can play a constructive role in the various stages of resolving a difference of opinion on the merits, apart from indicators of standpoints and arguments, such as "therefore" and "because," also indicators of other moves that play a part in critically testing the acceptability of the standpoint at issue can thus be included in the research. Which linguistic indicators signal, for example, that an arguer accepts the burden of proof for a standpoint or tries to evade the burden of proof? Which indicators refer to the point of departure of the discourse? And which indicators point to the result of the discussion? Third, the ideal model of a critical discussion enables the analyst to classify the various kinds of indicators in a systematic way, because the argumentative moves they refer to are systematically connected with the various stages in the resolution process.

Methodologically, we take the model of a critical discussion as our point of departure in identifying argumentative moves in argumentative practice, even in cases in which the moves concerned are potentially or actually fallacious. The model can be used as a frame of reference in identifying argumentative moves that are analytically relevant but may be irrelevant from an evaluative perspective, i.e., fallacious. ${ }^{15}$ As we explained earlier (e.g., van Eemeren and Houtlosser 2002), arguers who aim to resolve a difference of opinion make use of "strategic manoeuvring": the rhetorical exploitation of the margins for verbal action left by the arguers' dialectical obligations in the various stages of a critical discussion. The strategic manoeuvring is sound as long as it remains in agreement with the rules for critical discussion, but it may also derail and become fallacious. In practice it can, of course, not always be predicted in advance whether a particular instance of strategic manoeuvring will be sound or fallacious.

How do we envisage the process of identifying moves that are analytically relevant for resolving a difference by way of a critical discussion to take place? In the various overviews of the model of a critical discussion that have been given, the tasks a critical discussion requires the participants to perform are presented in a general way; not every potential contribution to the critical testing process is specified. ${ }^{16}$ In the overview of the opening stage, for example, the participants in a critical discussion have to come to an agreement about their mutual material and procedural starting points, but it is not specified which moves exactly they have to make to come

\footnotetext{
${ }^{15}$ For the conceptual distinction between analytical relevance and evaluative relevance, see van Eemeren and Grootendorst (1992b).

${ }^{16}$ In van Eemeren and Grootendorst (1984, 1992a, 2004) and van Eemeren et al. (1996) the stages are specified that the critical testing process has to go through and the crucial obligatory moves are represented. Snoeck Henkemans (1992) gives a specification of the first round of moves in the argumentation stage.
} 
to such an agreement. For our present purposes, however, a specification of these moves is needed, because it is not possible to identify the indicators of the various moves if their dialectical function has not been fully defined.

Instead of specifying all the moves a critical discussion could possibly consist of, out of necessity, we opt for a piecemeal approach and start specifying - in an exemplary way - those moves that can be instrumental in realizing some particular tasks the discussants have to perform at some particular stages or sub-stages of the discussion. In order to be able to do so, we have developed a heuristics consisting in the application of dialectical profiles. Our dialectical profiles are inspired by the idea of profiles of dialogue developed by Walton and Krabbe and presented in several publications (Walton 1989; Walton and Krabbe 1995; Krabbe 1992, 1999). Walton and Krabbe describe a profile of dialogue as "a connected sequence of moves and countermoves in a conversational exchange of a type that is goal-directed and can be represented in a normative model of dialogue" (Walton 1999, p. 53; Krabbe 1999, p. 2). Our dialectical profile is from the outset a purely normative concept and can be defined as a sequential pattern of the moves that the participants in a critical discussion are entitled - and in some sense obliged - to make to realize a particular dialectical aim in a particular stage or sub-stage of the discussion. In the next section we shall further explain what we mean by dialectical profiles by showing how they can be used as a design for capturing the moves that are instrumental at a particular stage or substage of a critical discussion. Our next step is to illustrate how we exploit the dialectical profiles methodically for identifying the verbal expressions that can be indicative of any of these moves in argumentative practice.

\section{DIALECTICAL PROFILES OF SEQUENCES OF MOVES IN A CRITICAL DISCUSSION}

In designing dialectical profiles, certain general principles are to be taken into account. The most prominent of them are: (a) a principle of systematicity that implies that the moves included in a particular profile must comply with the sequential order of the dialectical procedure; these moves can be single or complex, but they are made in turn, one at the time; (b) a principle of comprehensiveness that implies that a profile must include all the moves that are necessary for the achievement of the possible outcomes of the discussion stage concerned; (c) a principle of analyticity that implies that complex profiles must be "decomposed" as far as possible into simple profiles; (d) a principle of economy that implies that no moves in a profile may be repeated, except in the profile of the confrontation stage, where they may be repeated (only) once; (e) a principle of finiteness that implies that a dialectical profile must make it clear how for each branch of the profile a closure is achieved in a finite number of moves.

To get to a first example of a dialectical profile, we focus on the way in which in the opening stage of a critical discussion agreement is reached as to who will assume the burden of proof. In the simplest case, i.e., that of a single non-mixed dispute with one standpoint that meets with doubt, ${ }^{17}$ agreement about who will assume the burden of proof may consist in either a confirmation or a disconfirmation of the conditional obligation of the party that advanced the standpoint to defend this standpoint. In order to determine which of these two results has been achieved, it is helpful to have an understanding of the kind of deliberation that can lead to either of these results, and the moves that are made to achieve it. ${ }^{18}$ Such an understanding can be achieved with the help of a dialectical profile of the deliberation process.

\footnotetext{
17 See van Eemeren and Grootendorst $(1984,2004)$ for the distinction between non-mixed disputes, in which the other party merely doubts the first party's standpoint but has no standpoint of his own, and mixed disputes, in which the other party counters the first party's standpoint by advancing an opposite standpoint.

${ }^{18}$ We use the (non-technical) term deliberation to refer to the parties' (sub-)discussion about the point of departure for the discussion. Some authors prefer to label such deliberations "meta-dialogues" (see Krabbe 2003; Finocchiarro 2005; Mackenzie 1981).
} 
In designing this dialectical profile, the first issue we have to deal with is which party is to start the deliberation and what kind of move this party must make. According to the pragmadialectical procedure for conducting a critical discussion the party (let's say $P$ ) that has advanced a standpoint in the confrontation stage of the discussion may in the opening stage be challenged by the other party (let's say A) to defend this standpoint (van Eemeren and Grootendorst 2004). Once the challenging move has been made, it is up to $\mathrm{P}$ to respond. This response can consist of one of the following alternatives: $\mathrm{P}$ may either accept the challenge or refuse to accept it. If $\mathrm{P}$ accepts the challenge, this particular deliberation is over: it is agreed that in the argumentation stage of the discussion $\mathrm{P}$ will defend his standpoint. If $\mathrm{P}$ refuses to accept the challenge, A may react to this refusal in two ways. A's first option is to claim his right to maintain his doubt. Then, again, the deliberation is in fact over. A's second option is to ask P why he does not want to defend his standpoint. Then $\mathrm{P}$ must either retract his standpoint or initiate a procedural discussion in which he explains his reasons for not defending his standpoint here and now. The deliberation may then still go on with a discussion of P's reason-giving. As a reason for not wanting to defend his standpoint here and now, $\mathrm{P}$ can for instance say that $\mathrm{A}$ is such a well-skilled arguer that it might be a good idea if he played the devil's advocate and made an attempt to defend P's standpoint. A should, in turn, react to this proposal, etc. For now, we leave it at the following "starting profile":

1 A: $\quad$ Defend your Standpoint!

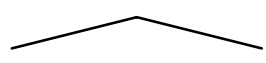

$2 \mathrm{P}: \quad$ OK. I accept the challenge No! I refuse to accept the challenge

3 A:

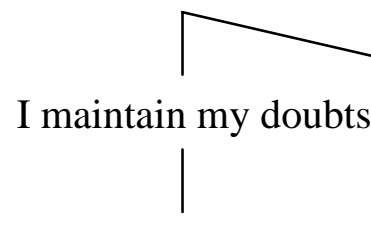

4 P:

$\ldots$

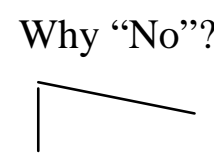

Reason- Retraction giving

In this way, the design of the profile provides the analyst with a systematic sequential representation of the moves that are analytically pertinent to the process of coming to an agreement about whether or not to accept a burden of proof for the standpoint at issue in the opening stage of the discussion.

\section{DETERMINING THE MATERIAL POINT OF DEPARTURE FOR THE DISCUSSION}

With the help of three extended examples we shall now explain how we make use of dialectical profiles for identifying indicators of argumentative moves. In this section we concentrate on indicators of moves that can - or have to - be made in the opening stage of a critical discussion to determine the material point of departure for the discussion.

Just as deliberations on the division of the burden of proof, deliberations aimed at achieving a material point of departure for the discussion that is shared by both parties need a beginning. Who has to make the first move and what kind of move should this be? Unlike the deliberation on accepting the burden of proof, the deliberation on the material point of departure for the discussion does not have a procedural rule that prescribes which party is to initiate the deliberation. This decision is left to the parties concerned. Let us assume that the party (P) that advanced the standpoint initiates the deliberation. How can he proceed? If we imagine the 
material point of departure for the discussion to consist of a set of mutually accepted propositions that comes about in a step-wise process in which all the propositions are in turn negotiated by the participants in the discussion, then the initial move in the deliberation on determining the point of departure consists in making a proposal to treat a certain proposition (X) during the discussion as a common point of departure.

How can A respond to P's proposal to treat proposition X as a point of departure for the discussion? Given that it is in the interest of both parties to have a joint point of departure for the discussion, A's response to P's proposal would be most efficient if it consisted in acceptance. It will be clear, however, that A may have all kinds of reasons not to accept $\mathrm{X}$ as a joint starting point. To be sure, A is under no obligation to give such a "preferred" response. The alternative response for A is to refuse P's proposal. There is, however, still a third possibility. Instead of accepting P's proposal or refusing it, A can accept P's proposal conditionally. By “accepting P's proposal conditionally" we mean that A is prepared to accept proposition X as a starting point for the discussion on the condition that $\mathrm{P}$ will do something in return - for instance, adopt yet another proposition, say $\mathrm{Y}$, as a starting point. There can be all kinds of reasons why the acceptance of $\mathrm{Y}$ by $\mathrm{P}$ would be expedient for $\mathrm{A}$, the most obvious reason being that $\mathrm{A}$ can use $\mathrm{Y}$ to counterbalance $\mathrm{X}$. The latter is, for example, the case if $\mathrm{Y}$ can serve to impose restrictions on the argumentative use that $\mathrm{P}$ can make of proposition $\mathrm{X}$ in defending his standpoint or, in a mixed dispute, if Y can be used by A to defend the opposite standpoint. ${ }^{19}$

The initiating proposal and the three possible reactions we have just discussed form together the first round of the deliberation concerning the material starting point for the discussion. In a dialectical profile this first round can be represented as follows:

1 P:

2 A:

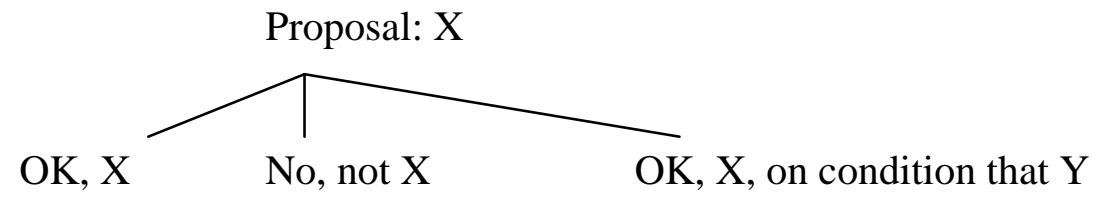

This profile of this first round of moves provides the analyst with a set of theoretically motivated options for the critical reconstruction of deliberations about the material starting point in a piece of argumentative discourse. In order to exploit this theoretical guidance, the analyst must, of course, be able to identify the manifestations of these moves when they occur and to provide an empirical, i.e., linguistic, justification for his analysis. This is where the examination of possible indicators of argumentative moves becomes important. Rather than discussing all potential indicators of the moves represented in the dialectical profile, we concentrate on making some general observations that are pertinent to all of them.

Our first observation concerning the expressions that are potential indicators of the moves in the profile - and argumentative moves in general - is that in argumentative practice not every move is necessarily accompanied by an indicator, let alone an unambiguous one. Imagine a scale that runs from linguistic indicators that are fully straightforward (e.g., "I hereby pronounce the standpoint that ...”) through implicit linguistic indicators (e.g., "by my

\footnotetext{
${ }^{19}$ The rationale for not including party A's questioning P's proposal (“Why X?") as a fourth possible response is that asking such a question would initiate a sub-discussion and for practical reasons we would like to restrict ourselves here to the discussion at the main level. For the distinction between discussions at the main level and discussions at a sub-level, see van Eemeren and Grootendorst (1984, 1992a, 2004).
} 
book") and functional and grammatical indicators (force of the speech act and mood of the sentence) to a complete lack of indicators.

A good example of the type of move that is as a rule not accompanied by a straightforward or even an implicit linguistic indicator is the first move in the profile: P's proposal to adopt proposition $\mathrm{X}$ as a starting point for the discussion. Explicit proposals to adopt a particular proposition as a starting point are in practice hardly ever made. A more likely way of suggesting one's interlocutor to adopt a proposition as a starting point would be to ask him whether he agrees that something is the case or is not the case, or that something should be done or should not be done. The only feature of the type of move that is indicative is then the interrogative mood. The interrogative mood, however, is a very weak indicator: it can also be used for a great variety of other types of moves, so that some very specific contextual information is required to justify the reconstruction as a proposal to adopt a proposition as a starting point for the discussion. ${ }^{20} \mathrm{~A}$ case in point are the questions asked by the doctor in the dialogue below, which is taken from van Eemeren et al. 1993:

Patient: $\quad$ I don’t want them ((my parents)) to have anything to do with my life, except (...) security

Doctor: $\quad$ You live at home?

Patient: $\quad$ Yes.

Doctor: $\quad$ They pay your bills?

Patient: Yeah.

Doctor: $\quad$ How could they not have anything to do with your life?

The doctor's first two moves are both questions; that is all the interrogative form of these moves tells us. The idea that these questions are asked to elicit concessions from the patient that enable the doctor to refute the patient's initial claim cannot be justified by merely referring to the interrogative mood. Because any straightforward or implicit linguistic indicators are lacking, this reconstruction can only be justified with the help of other sources, such as pragmatic insight in the standard patterns of such kinds of (critical) exchanges, in this case the pattern of punch-line refutation, as provided by discourse analysis.

There are, of course, also cases in which an implicit proposal to adopt a proposition as a starting point is functionally indicated in a more outspoken way. This is, for instance, the case when the proposal is presented as a rhetorical question, as in the following example (taken from Houtlosser 1995):

(4) Is it my fault that my looks are better than Ellen van Langen's?

(Stella Jongmans, de Volkskrant, January 10, 1994)

Asking a rhetorical question is a quite common means of proposing to adopt a proposition as a starting point. The problem with rhetorical questions, however, is that they are also used for other purposes, for instance to advance standpoints. The last question in the dialogue between the doctor and the patient is a case in point. There the standpoint is that the patient cannot afford to have nothing to do with his parents. Here is another example, taken from a conversation about going on holiday that we recently overheard:

\footnotetext{
${ }^{20}$ For the analyst, the degree of implicitness of the communicative "force" of a speech act corresponds conversely to the degree of contextual information that is needed to justify the reconstruction of the communicative function of that speech act. See, for instance, van Eemeren and Grootendorst (1992a).
} 
In this example it is decisive for the interpretation of the rhetorical question as a standpoint that the statement following the rhetorical question can be plausibly viewed as an argument in favor of the assertion that is indirectly conveyed by the rhetorical question, i.e., that Hank does not know anything about the place concerned (van Eemeren 1986; Slot 1993; Houtlosser 1995).

Asking a rhetorical question is in fact already half-way between making a proposal to adopt a proposition as a starting point and attributing this status, without any ado, to a proposition. A party $\mathrm{P}$ that does the latter is in fact ahead of events and acts as if his proposal to treat proposition $\mathrm{X}$ as a starting point for the discussion was already accepted by $\mathrm{A}$ without $\mathrm{P}$ having made any such proposal. Roughly speaking, two kinds of cases can be distinguished: (a) the proposition concerned is just used by $\mathrm{P}$ as an argument in the argumentation stage without any sign that it would not be acceptable to the other party; (b) the proposition is explicitly presented by $\mathrm{P}$ as if it were an already accepted starting point that can therefore be used as an argument. In case (a), the fact that $\mathrm{X}$ is used as an argument is in fact the only indicator that - at least according to $\mathrm{P}-\mathrm{X}$ was already accepted by $\mathrm{A}$ as a starting point. Case (b) can also be indicated explicitly. The funny thing is, however, that these indications are pre-eminently used in a perverted way: more often than not, they make it clear that what was presented as a common starting point is in reality not a common starting point at all: "There is no doubt that ...," "It will be clear that ...." and "Everybody knows that ...." If it would indeed be the case that everyone, including A, agreed that X is the case, why then "propose" the interlocutor to accept X as a starting point (Houtlosser 1995)?

What about the indicators of reactions to a proposal to adopt a proposition as a starting point for the discussion? Unlike the proposal itself, the reactions to the proposal specified in the dialectical profile regularly contain verbal elements that - under certain conditions - can be regarded as indicators of these moves. Of the three kinds of reactions that we specified, those of acceptance can be accompanied by markers such as "OK," "sure," "I agree" and "that is true" and those of refusal by markers such as "I don't think so" and "no." However simple these markers may seem, they are certainly not simple in the sense that the analyst can always rely on them. Obviously, expressions such as "OK" and "no" are used for a lot of other purposes than accepting or refusing a proposal to treat a certain proposition as a common starting point for a discussion.

The indicators accompanying reactions of conditional acceptance are more reliable. In the dialectical profile the move of conditional acceptance is specified as combining the adoption of one proposition (X) with a proposal to adopt simultaneously another proposition (Y). Odd as it may seem, in argumentative practice this combined move is not only often made but, on top of that, usually explicitly indicated. The indicator that is used (examples are the connectives "although," "nevertheless," and "but") indicates in such cases that there exists a conditional relationship between the propositions that the move combines.

The connective "but" is a word that has been subjected to a host of linguistic analyses; the most well-known of these is probably Ducrot's (1980) standard analysis, which supports our description. ${ }^{21}$ In the construction "X but Y," "but” (in Ducrot's analysis “mais") connects a proargument, $X$, that, from a certain viewpoint, favors a certain type of conclusion and a counterargument, $\mathrm{Y}$, that, from a different viewpoint, tells against that same type of conclusion; in addition, "but" conveys that the counter-argument $\mathrm{Y}$ overrules the pro-argument $\mathrm{X}$. This analysis applies to the combined move of conditional acceptance that is represented in our dialectical profile. After all, the main reason why party A only agrees to accept party P's proposal to adopt proposition $\mathrm{X}$ as a starting point on the condition that proposition $\mathrm{Y}$ is adopted as a starting point

\footnotetext{
${ }^{21}$ A difference with the situation envisioned in Ducrot's analysis is that in Ducrot's analysis $\mathrm{Y}$ is not first proposed but simply used.
} 
as well, is that Y can be used to overrule - or at least neutralize (Snoeck Henkemans 1995) - the argumentative use that $\mathrm{P}$ can make of $\mathrm{X}$. Thus, if "but" is employed in the way described in Ducrot's analysis, it indicates the move that in our profile is labeled a conditional adoption of a starting point.

Our analysis of "X but $\mathrm{Y}$ " as an indication of a move in which a proposition is conditionally adopted as a starting point has the interesting spin-off that it sheds more light on Ducrot's analysis of "X but $Y$ " in at least six ways. First, it explains how it is possible for a speaker to accept both $\mathrm{X}$ and $\mathrm{Y}$, in spite of their contradictory argumentative "orientation" (as Ducrot puts it) - in our analysis $\mathrm{X}$ and $\mathrm{Y}$ are not accepted as arguments but simply as propositions. Second, our analysis explains why the use of "but" is needed to "reconcile" two propositions that are content-wise not contradictory - although $\mathrm{X}$ and $\mathrm{Y}$ are accepted as propositions in the opening stage of the discussion, they are not accepted for their propositional content, but for their argumentative potential, which is to be exploited in the argumentation stage. Third, our analysis explains why in Ducrot's analysis the argument $\mathrm{X}$ and the counterargument $\mathrm{Y}$ presuppose different viewpoints $-\mathrm{X}$ is in our analysis proposed by one party and $\mathrm{Y}$ by the other party. Fourth, our analysis makes it clear that there exists a specific relationship between the viewpoints - the parties that represent these viewpoints are opponents in one and the same dispute. Fifth, as a consequence, Y can be said to be not only argumentatively relevant to $\mathrm{X}$, as it is in Ducrot's analysis, but also interactionally relevant - the party who proposes $\mathrm{Y}$ responds, after all, to the other party's proposal to accept $\mathrm{X}$. Sixth, our analysis explains why counter-argument Y in Ducrot's analysis is supposed to overrule pro-argument $\mathrm{X}$ - or at least to neutralize it: because $\mathrm{X}$ is accepted while having a certain argumentative potential in favor of the other party's standpoint, it must be assumed that the condition to accept $\mathrm{Y}$ as well is set because $\mathrm{Y}$ is supposed to have at least an equally large argumentative potential in favor of the party's own standpoint as X has in favor of the other party's standpoint. It would, after all, be useless to propose a starting point that has less argumentative potential than the starting point responded to. $^{22}$

\section{INDICATORS OF CAUSAL ARGUMENTS AND CRITICAL REACTIONS TO CAUSAL ARGUMENTS}

Our next observations pertain to indicators of moves that play a part in the actual testing procedure. First, we focus on moves in the procedure that applies when causal argumentation is presented and reacted to. The type of causal argumentation we are concerned with here consists of cause-consequence argumentation. In this type of argumentation, it is claimed that an event mentioned in the argument has led, leads, or will lead, to the event represented in the standpoint. The first move in the procedure is the presentation of such an argument by the protagonist of the standpoint that is to be defended. In response to this move, the antagonist can (1) accept the argument, (2) question whether the proclaimed cause of the event really causes that event, (3) question whether the proclaimed cause does not cause a different event than the one referred to in the standpoint, or (4) question whether the event that is supposedly caused by the proclaimed cause is not caused by something completely different. ${ }^{23}$

\footnotetext{
22 "But" can also play a part in rejecting a proposal to adopt a proposition as a starting point. When "but" is used in a dialogue to introduce a direct reaction to such a proposal in a dialogue, it indicates without any exception that an objection to this proposal is about to be advanced.

${ }^{23}$ These questions were earlier formulated and accounted for in the pragma-dialectical theory (van Eemeren and Kruiger 1985). (2) questions the supposed causal relation as such ("How on earth could you believe that smoking (automatically) causes lung cancer?”), while (3) and (4) can be viewed as specifications of (2). In (3) the antagonist suggests that the cause that is mentioned is not a sufficient cause to effectuate the consequence represented in the standpoint: there could be consequences that are different from, and perhaps even incompatible with, the one that is mentioned (as in “Couldn't it be the case that people like you precisely because you are sometimes a bit unfriendly to
} 
This is the dialectical profile of cause-consequence argumentation, where " $\mathrm{A}$ " is the argument, whose content consists of an accepted starting point " $\mathrm{X}$," " $\mathrm{S}$ " is the standpoint that represents the caused event, "T" represents a different event, and "U" represents a different cause, "=> " means "leads to," "?/” preceding a proposition means "I doubt whether" and "?" following a proposition refers to the interrogative mood:

$1 \mathrm{P}$ : (A \&) $A=>S$

2 A: OK

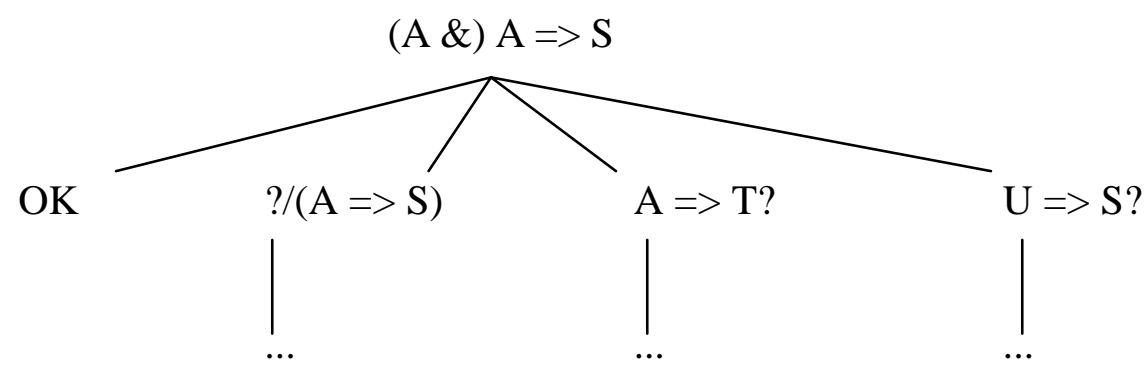

3 P:

There are a great many expressions referring to a causal relation that can serve as linguistic indicators of the move presenting a cause-consequence argument (Snoeck Henkemans 2001). Some expressions, such as "cause," "effect," "means," “end," "makes that," and "leads to," mention the causal relation explicitly. Other expressions refer only implicitly to the causal connection, mentioning just an aspect of the causal relationship. Among the latter are expressions such as "cultivate" that represent a process that produces a particular effect or result, expressions such as "suddenly" and "in one blow" that refer to the sudden way in which something has happened or come about, expressions such as "will yield" and "is a guarantee for" that allude to a future result, and expressions such as "necessarily" that emphasize the inevitability of an event. One example suffices to make it clear that such an indicator can be implicit and strong at the same time:

(7) [It is no small wonder that X was expelled. His approach was not subtle enough.] In Chinese politics, based as it is on prudence and strictness, a less-than-subtle approach is almost a guarantee for a rapid down-fall.

(de Volkskrant, March 18, 1998)

The next moves in the profile we need to discuss are the critical questions that can be asked in response to cause-consequence argumentation. It is noteworthy that it is not always the critical questions that are represented in the discourse, but the critic's negative answers to these questions. Apparently, critics have a hard time keeping the difference non-mixed at the sub-level. A likely negative answer to the first critical question associated with causeconsequence argumentation would be that the cause mentioned in the argument did not cause or will not cause the event referred to in the standpoint. Among the expressions that straightforward or implicitly - indicate such an answer are “does not lead to," “you don't get

them?" in response to "I am sure they hate me, because I'm so unfriendly sometimes"). In (4), the antagonist suggests that the supposed cause is not necessary to effectuate the consequence mentioned in the standpoint: apart from the cause that is mentioned in the argument, there could be, or there are, only other causes that have this consequence (as in "You become schizophrenic because of genetic features, not because of having had a coldhearted mother, don't you?” in critical reaction to "That one will become a schizophrenic, having the cold-hearted mother he has!”). (3) and (4) may, of course, subsume more specific critical reactions in which particular nuances of the mentioned aspects of the supposed causal relation are questioned. 
... from/by," "it has not been proven that," and "has nothing to do with." (8) is a - selfinvented - example:

Don't you know that it has never been proven that smoking kills, son?

Expressions that indicate a negative answer to the second critical question are "leads rather to," "is rather the cause of," and "has on the contrary everything to do with." Expressions that indicate a negative answer to the third critical question are "has a different cause," and "is rather caused by.”

In our dialectical profile we have left the protagonist's reply to the antagonist's critical questions unspecified. One obvious substantiation of this move is, of course, the protagonist's refutation of the antagonist's criticism. In practice, the protagonist's refutation of such criticism is generally anticipated in the argumentation. In written texts this will even be the standard procedure, because then there is no antagonist available to ask critical questions.

\section{INDICATORS OF COMPLEMENTARY COORDINATIVE ARGUMENTATION}

In an argument scheme, an individual argument is related to the standpoint it is supposed to support or refute. As a rule arguments also have a certain relationship with other arguments that are adduced to support or refute the same standpoint. Together, the arguments are then characterized by a certain more or less complex argumentation structure. The complexity of the argumentation structure depends to a large extent on the reactions that arguers get (or expect to get) to their argumentation (van Eemeren and Grootendorst 1984, 1992a, 2004; Snoeck Henkemans 1992). What structure the resulting complex of arguments will have, depends on the criticism and on the way in which the protagonist defends himself against this criticism (Snoeck Henkemans 1992).

Complex argumentation can take several forms. When the propositional content of an argument advanced by the protagonist is not accepted by the antagonist, the protagonist can support this argument by advancing another argument. Then the argumentation structure becomes subordinative. ${ }^{24}$ The argumentation structure becomes coordinative when the protagonist's argument is not doubted as such but deemed insufficient, or when the antagonist makes a specific objection to the protagonist's argument. In the first case, the protagonist may supply an additional argument in response, which makes the coordinative structure of his argumentation cumulative. In the second case, the protagonist may attempt to meet the objection, which makes his coordinative argumentation complementary. Finally, the argumentation structure may also become multiple. This happens when the antagonist rejected the protagonist's argument or the defense it is supposed to give of his standpoint and the protagonist decides not to defend this argument, but to defend his standpoint with a completely different argument.

The various possible ways of not accepting a protagonist's argumentation are represented in the dialectical profile below, where "A1," "A2" and "A1.." are the protagonist's arguments or sub-arguments, "-> " means "supports" or "refutes," "S" is the protagonist's standpoint, "?/” means "I have doubts with respect to," "\&" means "and," "[A $\mathrm{A}_{1}=\mathrm{A}_{1} \mathrm{a}$ \&]" means that the antagonist considers $A_{1}$ only as a beginning of a defense of $S$, "C" is an objection or counterargument, “//” means "pleads against," "|" means “or," " ” means "it is not the case that,"

\footnotetext{
${ }^{24}$ Strictly speaking, the content of the argument that the protagonist has advanced can at this stage of a critical discussion no longer be subjected to critical scrutiny because, if all has gone well, it has been accepted (or not accepted) by both parties as a common starting point at the opening stage of the discussion. In practice, however, starting points are not always proposed as such, but simply used as arguments in the argumentation stage of the discussion. We therefore include the questioning of the content of a starting point that is used in an argument in the argumentation stage in our dialectical profiles.
} 
“+” means that the arguments must be taken together, and "DS!" means that a renewed challenge is made with regard to the initial standpoint.

(8)

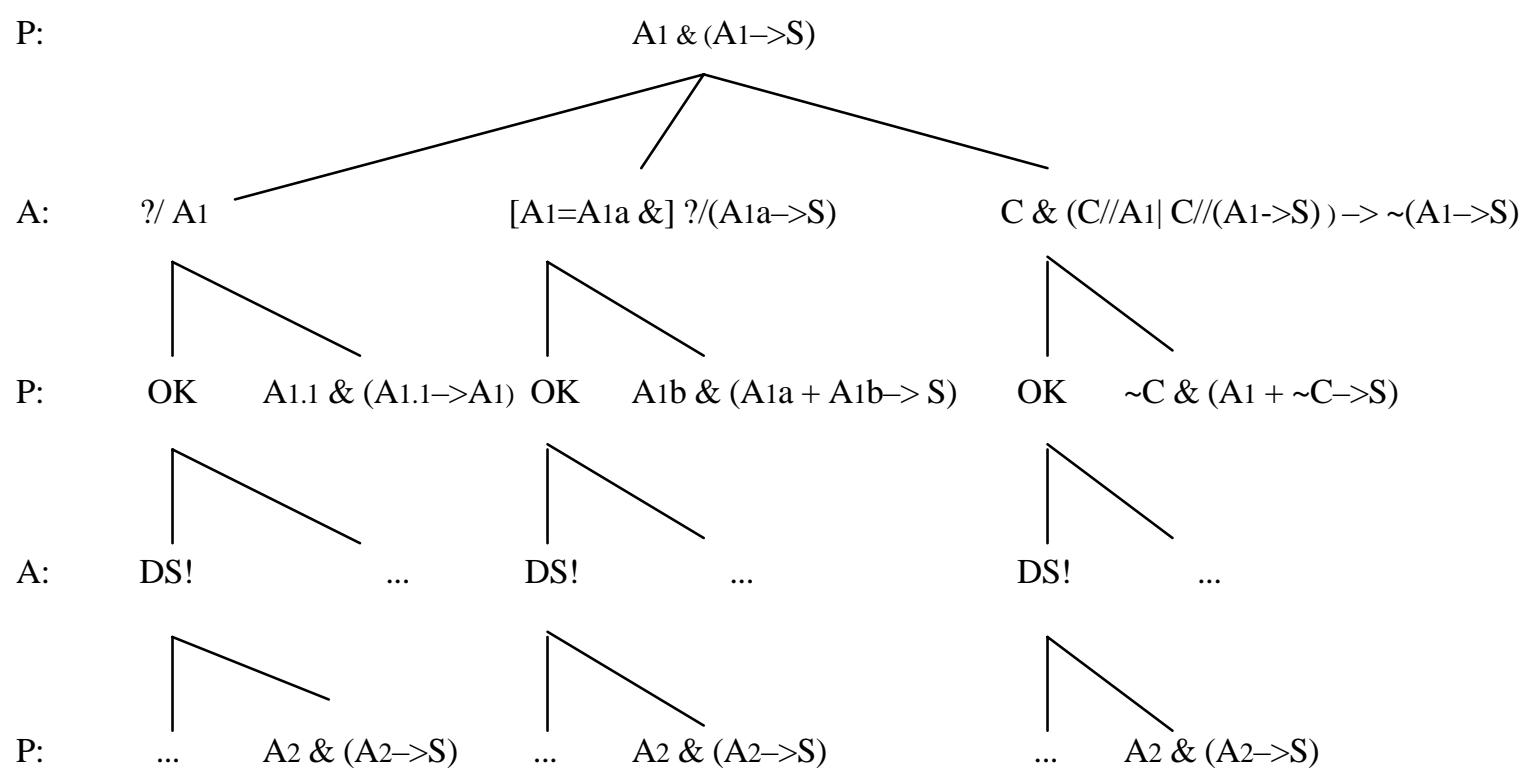

We here shall concentrate on some indicators of complementary coordinative argumentation. First we give an example of the way in which complementary coordinative argumentation emerges in a dialogical situation, then we focus on indicators of complementary coordinative argumentation in implicit discussions or monologues.

In dialogue (9), overheard at Paula's place at lunch, Anton regards Paula's argument that the last bus had already left an inadequate argument for Paula's staying the night at Eric's. He counters this argument by saying that Paula could have asked Anton to come and pick her up. Paula refutes Anton's counterargument by saying that she did not want to wake him up. In this way, a complementary coordinative argumentation is brought about:

(9) Paula: I had no choice but to stay the night at Eric's because the last bus had already left. Anton: But you could have asked me to come and pick you up.

Paula: But I didn't want to wake you up.

In monologues, complementary coordinative argumentation is put forward by the protagonist if he anticipates that an objection against one of his arguments may be advanced that attacks the justificatory potential of this argument. Anticipating this criticism, the protagonist adds another argument that is supposed to parry the criticism. In combination, the argument that supports the standpoint directly and the refutation of a possible objection to this argument constitute, again, a complementary coordinative argumentation.

There are a number of expressions that an arguer can use to indicate that a possible objection against an earlier argument will be refuted. Among these are "while," "whereas," "whereas normally," "whereas otherwise," "not even" and "and yet." Expressions such as "whereas," "while" and "and yet" can be used by the protagonist to signal a contrast between the views or criticism of a potential opponent and the way he thinks things are in reality. The following argument is an example of this use of "whereas": 
(10) I wrote a letter to the administrative council, saying I can't tell you how much I appreciate the stipend. It has allowed me to dedicate so much of my time to SG, whereas otherwise I would have worked a campus job to pay the bills. (www.studentleader.com/sal_r.htm)

In this example, a student defends the standpoint that his stipend has been a great help because it has allowed him to dedicate a lot of time to student government. A critical opponent might wonder: but couldn't you have devoted that time to student government without the stipend? The arguer makes clear that this criticism does not hold, because then he would have had to take a campus job to pay the bills and that would have interfered with his involvement in extracurricular activities.

Just like happens in the student example, "whereas" or "while" can be easily combined with expressions such as "otherwise" or "normally." This is in particular so in cases where the arguer is defending a positive or negative judgment or qualification and needs to take into account that his opponent might come up with criticisms such as "But does your argument really justify that judgment?" "Is the situation or event that you mention in your argument not something that is always or normally the case, so that the judgment that there is something special about the case (i.e. something negative or positive) cannot be justified?” By indicating that otherwise things would have gone differently, or that normally something would not have been the case, the arguer can make it clear that the potential objections against the first argument do not hold and that the positive or negative judgment is therefore indeed justified. In example (11) "and yet" is used to make it clear that a possible objection does not hold:

(11) We, at Breton Bikes, are based in Brittany. This is the Celtic homeland of France, and having cycle toured all over France we can say that this is the best bit. Why? Because here the countryside is small scale, perfect for cycling, and yet within easy reach of us you will find beautiful unspoiled countryside, two different and quite stunning coasts and a heartland of forests and lakes, canals and chateaux (www.bicycletouring.biz).

The protagonist first claims that Brittany is the best part of France for cycling, because the countryside there is small scale and then anticipates the objection that if the countryside is smallscale, it will probably not be very interesting. The anticipated objection is signaled by "and yet" and the protagonist counters this objection by mentioning examples of interesting scenery and culture in Brittany, thus giving a complementary coordinative structure to his arguments in the process.

\section{CONCLUSION}

In this article, we have shown how the use of dialectical profiles can be instrumental in determining which moves can be made in a particular stage of a critical discussion and in identifying the expressions that are indicative of these moves. We conclude by mentioning some other applications of dialectical profiles. In addition to their heuristic function in the identification of indicators of argumentative moves, dialectical profiles also have an important heuristic role in the analysis of strategic manoeuvring. Because every dialectical move specified in a dialectical profile allows for rhetorical exploitation, every move in the dialectical profile can be an occasion for strategic manoeuvring. This makes the dialectical profile not only the best source for identifying the dialectical moves that the parties must make in conducting a critical discussion but also for identifying the ways of strategic manoeuvring the arguers can deploy to steer the critical resolution process into their own direction. 
ACKNOWLEDGMENTS: This article was written as part of the project "Argumentative indicators in Dutch" subsidized by the Netherlands Organization for Scientific Research NWO (project no. 200-41-012). We would like to thank M. Agnès van Rees, Assimakis Tseronis, and Erik C.W. Krabbe, as well as the participants in the Wake Forest/ISSA Conference held in Venice, June 2004, for their constructive comments on earlier versions of this paper.

$\underline{\text { link to commentary }}$

\section{REFERENCES}

Albert, H. (1975). Traktat über kritische Vernunft ( $3^{\text {rd }}$ edition). Tübingen: Mohr.

Austin, J.L. (1962). How to Do Things with Words. Oxford: Clarendon Press.

Barth, E.M. and E.C.W. Krabbe, E.C.W. (1982). From Axiom to Dialogue. A Philosophical Study of Logics and argumentation. Berlin/New York: Walter de Gruyter.

Ducrot, O. et al. (1980). Les mots du discours. Paris: Les Éditions de Minuit.

Eemeren, F.H. van (1986). Dialectical analysis as a normative reconstruction of argumentative discourse. Text 6, $1-16$.

Eemeren, F.H. van (2002, Ed.). Advances in Pragma-Dialectics. Amsterdam/Newport News: Sic Sat/Vale Press.

Eemeren, F.H. van and R. Grootendorst (1984). Speech Acts in Argumentative Discussions. A Theoretical Model for the Analysis of Discussions Directed Towards Solving Conflicts of Opinion. Dordrecht/Berlin: Foris Publications/Mouton de Gruyter.

Eemeren, F.H. van and R. Grootendorst (1992a). Argumentation, Communication and Fallacies. A PragmaDialectical Perspective. Hillsdale, N.J.: Lawrence Erlbaum Associates.

Eemeren, F.H. van and Grootendorst, R. (1992b). Relevance reviewed: The case of argumentum ad hominem. Argumentation 6, 141-159.

Eemeren, F.H. van and Grootendorst, R. (2004). A Systematic Theory of Argumentation. The Pragma-Dialectical Approach. Cambridge: Cambridge University Press.

Eemeren, F.H. van, R. Grootendorst, S. Jackson and S. Jacobs (1993). Reconstructing Argumentative Discourse. Tuscaloosa/London: The University of Alabama Press.

Eemeren, F.H. van, R. Grootendorst, A.F. Snoeck Henkemans, J.A. Blair, R.H. Johnson, E.C.W. Krabbe, C. Plantin, D.N. Walton, C.A. Willard, J. Woods, and D. Zarefsky (1996). Fundamentals of Argumentation Theory. A Handbook of Historical Backgrounds and Contemporary Developments. Mahwah, NJ: Lawrence Erlbaum.

Eemeren, F.H. van and P. Houtlosser (2002). Strategic maneuvering in argumentative discourse: A delicate balance. In: F.H. van Eemeren and P. Houtlosser (Eds.), Dialectic and Rhetoric. The Warp and Woof of Argumentation Analysis (pp. 131-159). Dordrecht: Kluwer Academic Publishers.

Eemeren, F.H. van, P. Houtlosser and A.F. Snoeck Henkemans (2000).Indicatoren van dialectische geschilprofielen [Indicators of dialectical profiles of types of disputes]. Tijdschrift voor Taalbeheersing 22, 112-125.

Eemeren, F.H. van, P. Houtlosser and A.F. Snoeck Henkemans (2000). Argumentatieve indicatoren in het Nederlands. Een pragma-dialectische studie. Amsterdam: Rozenberg Publishers. [To be published in English as Argumentative Indicators in Discourse. A Pragma-Dialectical study. Dordrecht: Springer, 2007]

Eemeren, F.H. van and T. Kruiger (1985). Het identificeren van argumentatieschema's [Identifying argument schemes]. In: Koning, W.K.B. (Ed.), Taalbeheersing in theorie en praktijk (pp. 55-66). Dordrecht/Cinnaminson : Foris.

Finocchiaro, M.A. (2005). Arguments about Arguments. Cambridge: Cambridge University Press.

Grice, H.P. (1989). Studies in the Ways of Words. Harvard: Harvard University Press.

Hamblin, C.L. (1970). Fallacies. London: Methuen.

Heritage, J. (1984). A change-of-state token and aspects of its sequential placement. In: J.M. Atkinson and J. Heritage (Eds.), Structures of Social Action. Studies in Conversation Analysis (pp. 299-346). Cambridge: Cambridge University Press.

Houtlosser, P. (1994). The speech act "advancing a standpoint.” In: F.H. van Eemeren and R. Grootendorst (Eds.), Studies in Pragma-Dialectics (pp. 165-171). Amsterdam: Sic Sat.

Houtlosser, P. (1995). Standpunten in een kritische discussie. Een pragma-dialectisch perspectief op de identificatie en reconstructie van standpunten [Standpoints in a Critical Discussion. A PragmaDialectical Perspective of the Identification and Reconstruction of Standpoints]. With a summary in English. Amsterdam: IFOTT. 
Houtlosser, P. (1997). Indicatoren van protagonisme [Indicators of protagonism]. Taalbeheersing 19, $196-206$.

Houtlosser, P. (2002). Indicators of a point of view. In: F.H. van Eemeren (Ed.), Advances in Pragma-Dialectics (pp. 169-184). Amsterdam/Newport News, VA: Sic Sat/Vale Press.

Jackson, S. (1992). "Virtual standpoints” and the pragmatics of conversational argument. In: F.H. van Eemeren, R. Grootendorst, J.A. Blair and C.A. Willard (Eds.), Argumentation Illuminated (pp. 260-269). Amsterdam: Sic Sat.Jackson, S, and S. Jacobs (1980). Of conversational argument: Pragmatic bases for the enthymeme. Quarterly Journal of Speech 66, 251-265.

Jackson, S, and S. Jacobs (1981). Argument as a natural category: The routine grounds for arguing in natural conversation. Western Journal of Speech Communication 45, 118-132.

Jackson, S, and S. Jacobs (1982). Conversational argument: A discourse analytic approach. In: J.R. Cox and C.A. Willard (Eds.), Advances in Argumentation Theory and Research (pp. 205-237). Carbondale: Southern Illinois University Press.

Jacobs, S. and S. Jackson (1983). Strategy and structure in conversational influence attempts. Communication Monographs 50, 285-304.

Krabbe, E.C.W. (1992). So what? Profiles for relevance criticism in persuasion dialogues. Argumentation 6, 271-283.

Krabbe, E.C.W. (1999). Profiles of dialogue. In: J. Gerbrandy, M. Marx, M. de Rijke and Y. Venema (Eds.), JFAK. Essays Dedicated to Johan van Benthem on the Occasion of his 50th Birthday, III. Amsterdam: Amsterdam University Press, 25-36.

Krabbe, E.C.W. (2003). Metadialogues. In: F.H. van Eemeren, J.A. Blair, Ch.A. Willard and A.F. Snoeck Henkemans (Eds.), Anyone Who Has a View. Theoretical Contributions to the Study of Argumentation. Dordrecht: Kluwer Academic Publishers, 83-90.

Levinson, S.C. (1983). Pragmatics. Cambridge: Cambridge University Press.

Lorenzen, P. and K. Lorenz (1978). Dialogische Logik. Darmstadt: Wissenschaftliche Buchgesellschaft.

Mackenzie, J.D. (1981). The dialectics of logic. Logique et Analyse 24, 159-177.

Naess, A. (1966). Communication and Argument. Elements of Applied Semantics (English translation of Om meningsytring. En del elementaere logiske emner. Universitetsforlaget, Oslo, 1947). London: Allen and Unwin.

Perelman, C. and L. Olbrechts-Tyteca (1958). La nouvelle rhétorique. Traité de l'argumentation. Paris: Presses Universitaires de France.

Perelman, C. and L. Olbrechts-Tyteca (1969). The New Rhetoric. A Treatise on Argumentation (English translation of Perelman, C. and L. Olbrechts-Tyteca 1958). Notre Dame/London: University of Notre Dame Press.

Popper, K.R. (1972). Objective Knowledge. An Evolutionary Approach. Oxford: Clarendon Press.

Popper, K.R. (1974). Conjectures and Refutations. The Growth of Scientific knowledge. London: Routledge \& Kegan Paul.

Searle, J.R. (1969). Speech Acts. An Essay in the Philosophy of Language. Cambridge: Cambridge University Press.

Searle, J.R. (1979). Expression and Meaning. Studies in the Theory of Speech Acts. Cambridge: Cambridge University Press.

Slot, P. (1993). “How Can You Say That?” Rhetorical Questions in Argumentative Texts. Amsterdam: IFOTT.

Snoeck Henkemans, A.F. (1992). Analysing Complex Argumentation. The Reconstruction of Multiple and Coordinatively Compound Argumentation in a Critical Discussion. Amsterdam: Sic Sat.

Snoeck Henkemans, A.F. (2001). Argumentation, explanation, and causality: An exploration of current linguistic approaches to textual relations. In: T. Sanders, W. Spooren and J. Schilperoord (Eds.), Text Representation. Linguistic and Psycholinguistic Approaches. Amsterdam/Philadelphia: John Benjamins, 231-246.

Snoeck Henkemans, A.F. (2003a). Indicators of analogy argumentation. In: F.H. van Eemeren, J.A. Blair, C.A. Willard and A.F. Snoeck Henkemans (Eds.), Proceedings of the Fifth Conference of the International Society for the Study of Argumentation. Amsterdam: Sic Sat, 969-973.

Snoeck Henkemans, A.F. (2003b). Indicators of argumentation structures. In: J.A. Blair, D. Farr, H.V. Hansen, R.H. Johnson and C.W. Tindale (Eds.), Informal Logic@25: Proceedings of the Windsor Conference. CD-ROM, Windsor, ON: OSSA.

Toulmin, S.E. (1958). The Uses of Argument. Cambridge: Cambridge University Press.

Tsui, A.B.M. (1991). The pragmatic functions of 'I don’t know'. Text 11, 4, 607-622.

Walton, D.N. (1989). Question-Reply Argumentation. New York: Greenwood Press.

Walton, D.N. (1999). Profiles of dialogue for evaluating arguments from ignorance. Argumentation 13, 53-71.

Walton, D.N. and E.C.W. Krabbe (1995). Commitment in Dialogue. Basic Concepts of Interpersonal Reasoning. Albany, NY: State University of New York Press. 